\title{
Disease Dynamics of Sclerotinia sclerotiorum on Stevia in North Carolina
}

Alyssa M. Koehler and H. David Shew, Department of Entomology and Plant Pathology, North Carolina State University, Raleigh 27695 Accepted for publication 19 April 2017.

Stevia (Stevia rebaudiana) is a perennial plant native to Paraguay that is currently emerging as a new crop in the United States. Stevia leaves contain multiple glycosides extracted for use as a natural, low-calorie sweetener (Gutierrez and Shew 1998). Production of stevia in North Carolina began in 2011. In current U.S. production practices, stevia seeds are sown in a greenhouse float-tray system, seedlings are transplanted to the field eight to 10 weeks after seeding, and plants are harvested once during the first year of growth. Stevia harvest typically occurs before flowering in early September. At frost, all aboveground parts of the plant die, while roots and crowns remain alive over the winter. New shoots emerge in March to April, with two harvests per season in the second and third years of production.

In 2013, white mold caused by Sclerotinia sclerotiorum was observed on young second-year plants (Kinghorn 2003). Symptoms

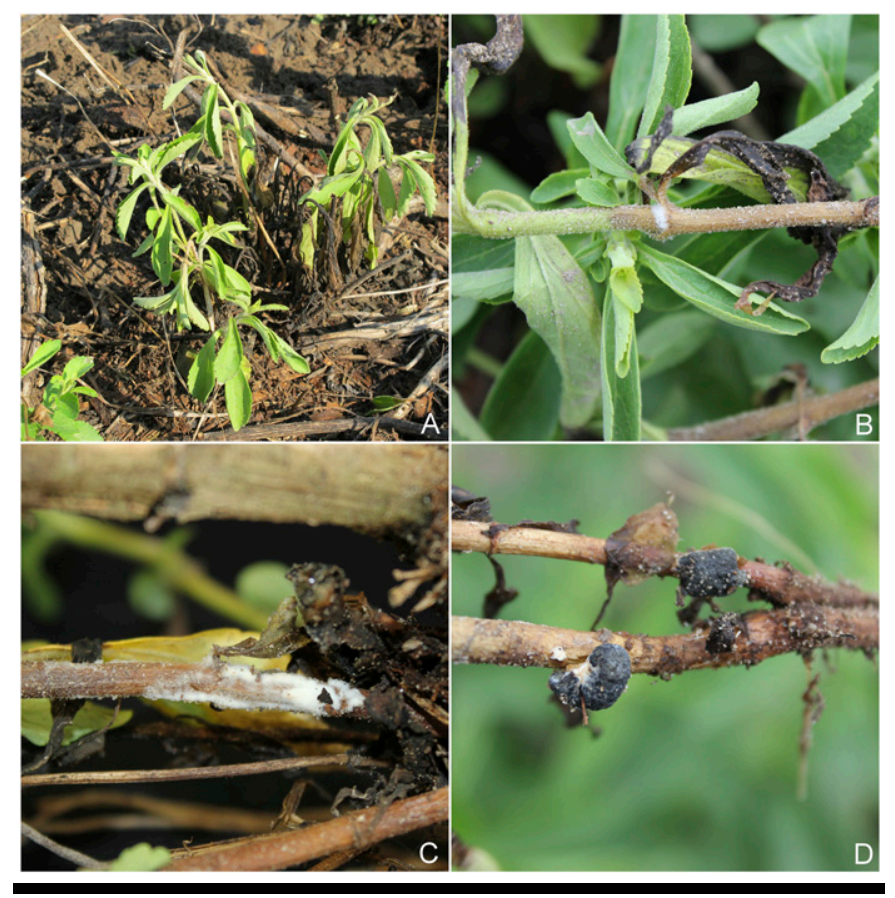

\section{FIGURE 1}

Field symptoms of Sclerotinia sclerotiorum on Stevia: (A) plants displaying wilting and necrosis caused by stem rot; (B) stem bleaching, necrotic leaves, and hyphae; (C) tufts of white hyphae at the base of the stem; and (D) mature sclerotia and stem bleaching.

Corresponding author: A. M. Koehler; E-mail: amkoehle@ncsu.edu

(C) 2017 The American Phytopathological Society included wilting, chlorotic leaves, necrotic leaves, bleached stem lesions, and dead stems. Symptomatic stems often had tufts of white hyphae and large, irregularly shaped, black sclerotia present on the base of the stem (Fig. 1).

Spore trapping was conducted from 2014 to 2016 using a semiselective $\mathrm{pH}$-indicator medium to detect and quantify ascospores in stevia fields and help determine if ascospores serve as primary inoculum for the disease (Koehler and Shew 2014). In October to November 2014, Petri dishes of the semiselective medium were set out weekly across a field of first-year plants in Kinston, NC, and very few ascospores were trapped. In spring 2015, trapping in the same field detected ascospores through the entire month of March, often with multiple spores caught per plate after a 1-h exposure (Fig. 2). A frost event on 28 March damaged many of the newly emerging second-year stems. No ascospores were trapped in April and first symptoms of $S$. sclerotiorum were observed on 23 April (Fig. 3). Individual stems within the cluster of stems from each crown were

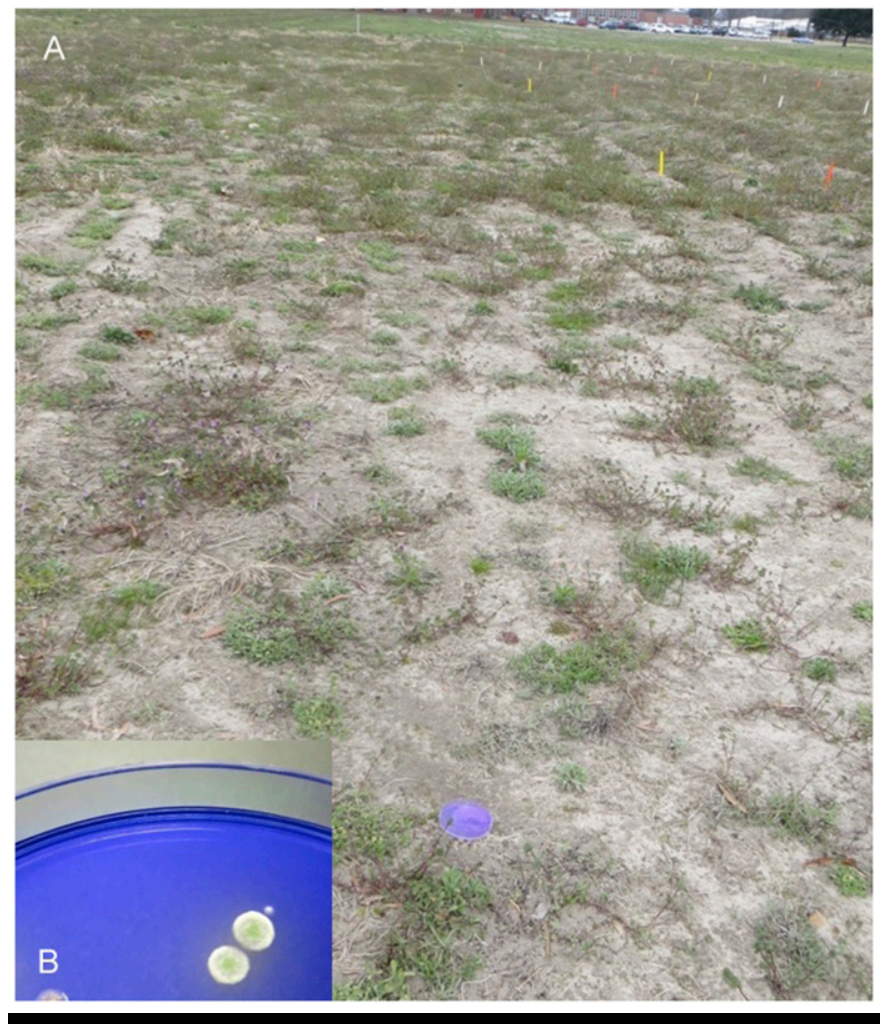

FIGURE 2

(A) Spring spore trapping using a semiselective $\mathrm{pH}$ indicator medium plate. (B) Ascospores of S. sclerotiorum. 


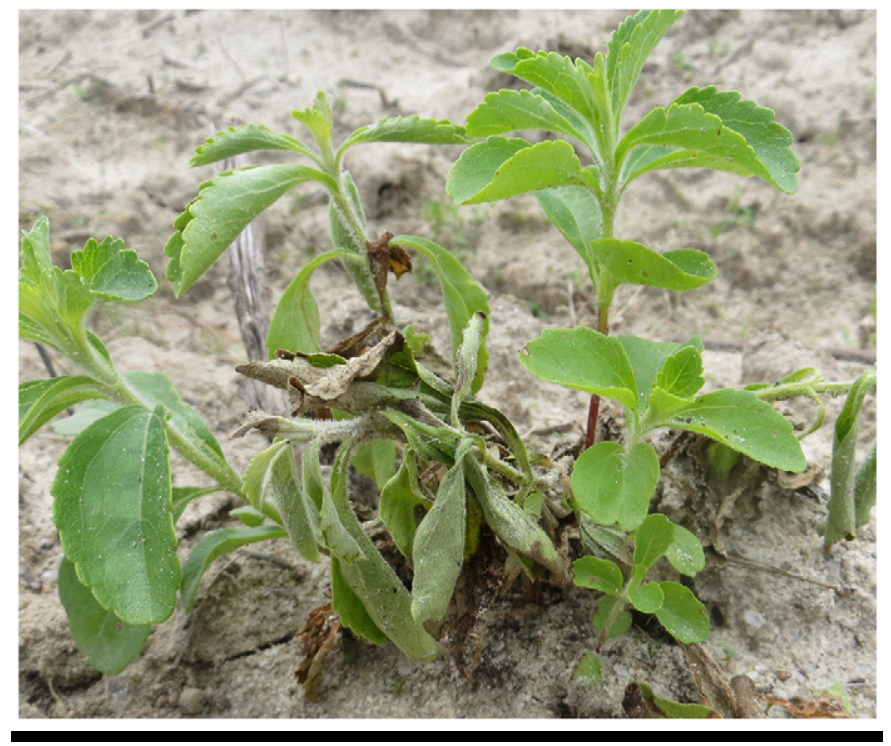

FIGURE 3

Emerging stevia stems displaying symptoms of S. sclerotiorum infection.

killed, but no secondary spread was observed. A new field trial was established in June 2015 in the same field. Again, limited ascospore release was detected in fall 2015 and no symptoms were observed. In spring 2016, ascospores were trapped from 1 March through the first week of April. Frost events on 5 and 9 April again damaged tender emerging stems and first symptoms on the second-year plants were observed on 11 May. Based on spring ascospore detection and no observations of direct stem infection in either year, it appears that ascospores are the primary inoculum of this pathogen on stevia and infection is favored on tissue damaged by frost. Timing of ascospore release in the spring supports observations of $S$. sclerotiorum occurring only on second- and third-year crops, since first-year plants are typically planted in May, after the period of ascospore release.

In 2015, ascospore infection resulted in death of individual stems, but hyphal growth from diseased stems was limited (Fig. 4). In 2016, disease dynamics were quantified in three fields. Sixty-seven multistemmed plants in Harnett, Lenoir, and Edgecombe counties were flagged and observed over a six-week period for secondary spread from symptomatic stems. Healthy stems of each plant were counted weekly to monitor stem loss. Across all sites, $S$. sclerotiorum infection caused an average loss of $47 \%$ of emerging stems per crown. On $74 \%$ of plants monitored, all stem loss occurred within the first three weeks of initial symptom development. Over the entire observation period, healthy

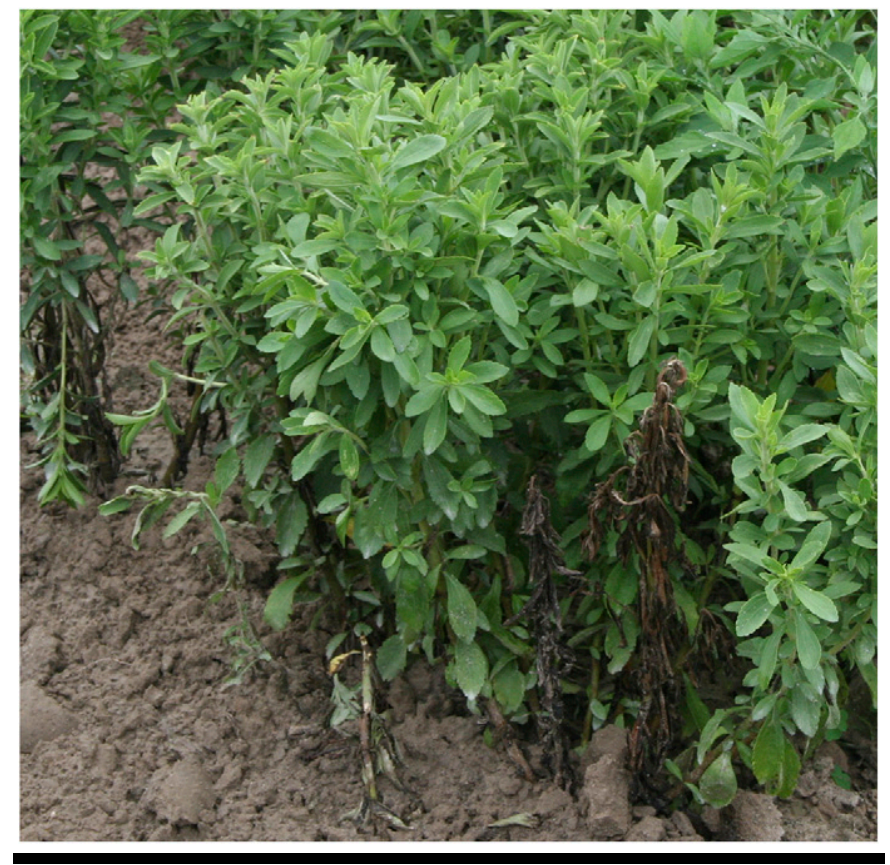

FIGURE 4

Symptomatic and healthy stems within a single plant.

stems adjacent to symptomatic stems did not become diseased, indicating disease was developing from initial infections and not from secondary spread of this pathogen. Stevia plants are multistemmed, with new shoots emerging throughout the season that allow for compensation of early-season stem loss. With the multistem growth habit of stevia and the lack of secondary spread by S. sclerotiorum, white mold is only a spring disease and is not expected to significantly impact yield potential of stevia in North Carolina. It should not require the application of fungicides in the field.

\section{Literature Cited}

Gutierrez, W., and Shew, H. 1998. Identification and quantification of ascospores as the primary inoculum for collar rot of greenhouse-produced tobacco seedlings. Plant Dis. 82:485-490.

Kinghorn, A. D. 2003. Stevia: The Genus Stevia. Taylor and Francis, New York, NY.

Koehler, A., and Shew, H. 2014. First report of stem rot of stevia caused by Sclerotinia, sclerotiorum in North Carolina. Plant Dis. 98:1433. 